\title{
Genetic heterogeneity in hereditary haemorrhagic telangiectasia: possible correlation with clinical phenotype
}

Kimberly A McAllister, Felicia Lennon, Barbara Bowles-Biesecker, Wendy C McKinnon, Elizabeth A Helmbold, Dorene S Markel, Charles E Jackson, Alan E Guttmacher, Margaret A Pericak-Vance, Douglas A Marchuk

\begin{abstract}
Hereditary haemorrhagic telangiectasia (HHT) or Osler-Weber-Rendu syndrome is an autosomal dominant vascular dysplasia characterised by recurrent haemorrhage. Our initial linkage studies found an HHT gene to be localised to $9 q 3$ in two large kindreds. In the present study, we examine an additional five unrelated HHT families. Linkage analysis in this region resulted in a peak multipoint location score of $13.03,10 \mathrm{cM}$ proximal of D9S60. We found significant evidence for heterogeneity of HHT. Multipoint analysis supports the family specific two point studies with odds of $3000000: 1$ showing linkage and heterogeneity over linkage and homogeneity. Four of the seven families give a posterior probability of $>\mathbf{9 9} \%$ of being of the linked type, and three families appear unlinked to this region of $9 q$, and by multipoint analysis completely exclude the candidate region for HHT. Two new crossovers in affected persons in one of the linked families further define the proximal border of the candidate region on $9 \mathrm{q} 3$.

A possible correlation in clinical phenotype between the $9 \mathrm{q} 3$ linked families and unlinked families is described. Although six of the seven families clearly meet the clinical criteria for HHT diagnosis, a significant absence of pulmonary arteriovenous malformations is seen in all three 9q3 unlinked families. Genetic heterogeneity of HHT and its potential correlation with a clinical phenotype may have a significant impact on the clinical management and treatment of HHT patients.
\end{abstract}

\section{( $\mathcal{F}$ Med Genet 1994;31:927-932)}

Hereditary haemorrhagic telangiectasia or Osler-Rendu-Weber (HHT), the official GDB designation of the disease, is an autosomal dominant disorder of multisystemic vascular dysplasia with an estimated incidence of approximately 1 in 50000 . The three primary types of angiodysplasia exhibited are arterial venous malformations (AVMs, particularly pulmonary and cerebral), telangiectases (mucosal, dermal, and visceral), and aneurysms. Penetrance is age dependent and is nearly complete by the age of 40 .
The most common clinical feature of HHT is recurrent epistaxis from vascular lesions in the nasal epithelium, which occurs in approximately $90 \%$ of HHT patients and is often the first identifiable feature of the disease. Gastrointestinal bleeding occurs in approximately $20 \%$ of HHT patients, but is often not seen until the fourth or fifth decade of life. Telangiectases, which are seen in approximately $70 \%$ of affected persons, are vascular abnormalities originating from capillaries and postcapillary venules that are most commonly seen on the face and lips and frequently on the trunk and limbs.

Pulmonary arteriovenous malformations (PAVMs), occurring in approximately $20 \%$ of HHT patients, are often asymptomatic until the third or fourth decade of life and are often only identified when serious complications result. Much of the estimated $10 \%$ mortality of HHT is associated with the two serious complications of undetected PAVMs: strokes and brain abscesses.

Neurological manifestations from central nervous system angiodysplasia can also be seen in HHT. Approximately $10 \%$ of patients have cerebral AVMs and 7\% have cerebral aneurysms, which can result in cerebral haemorrhage. ${ }^{1}$ Another common neurological manifestation is migraine headache, appearing in up to $50 \%$ of affected persons. These have been postulated to be the result of undiagnosed PAVMs. ${ }^{2}$

The diffuse constellation of symptoms has been extensively studied and incidence rates have been calculated in a number of retrospective and prospective studies. ${ }^{2-5}$ Great variability of expression is seen with a wide disparity of clinical features even among members of the same family, indicating that factors other than the inherited germline mutation determine the individual phenotype. However, it is unclear whether all families present the entire spectrum of clinical features. Any differences might be attributable to either allelic or non-allelic heterogeneity. Genetic linkage for some HHT families has recently been established to markers on $9 \mathrm{q} 3 .^{6-8}$ Genetic heterogeneity has been suggested by a single family unlinked to this region. ${ }^{8}$ The extent of genetic heterogeneity and its relationship to the clinical heterogeneity of HHT has not been addressed.
Received 13 June 1994 Revised version accepted fo publication 9 August 1994 

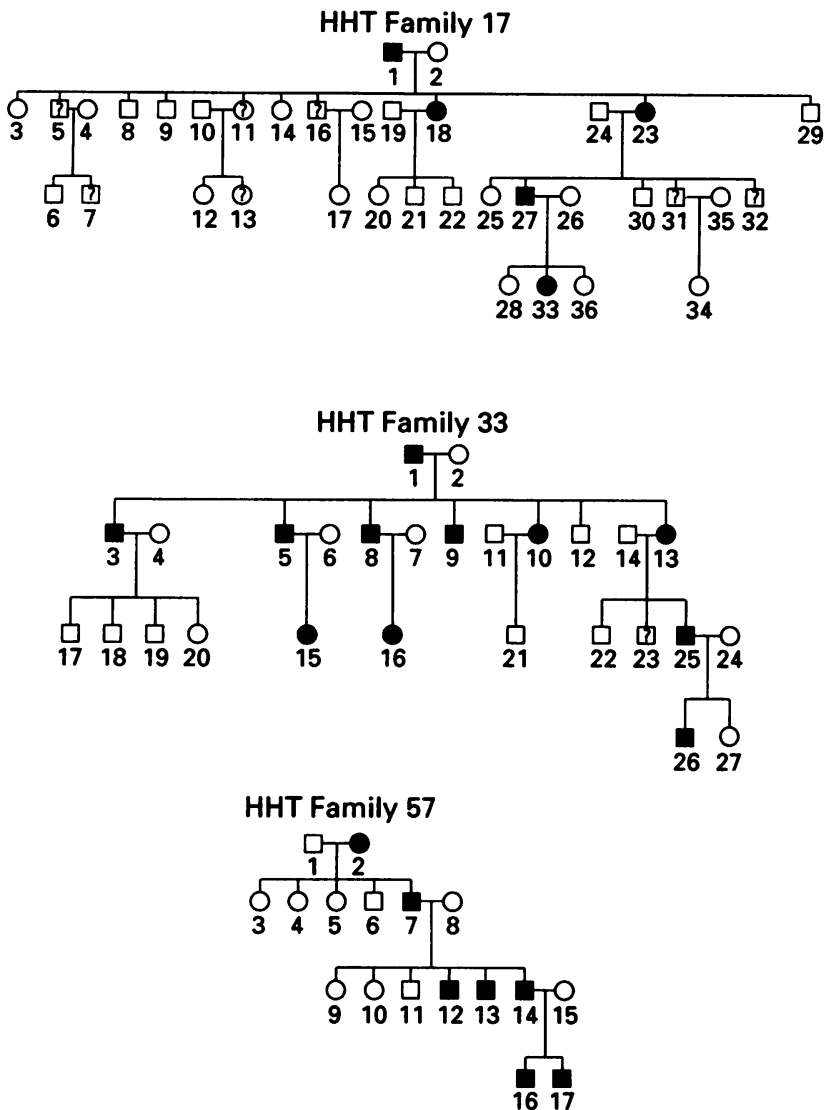
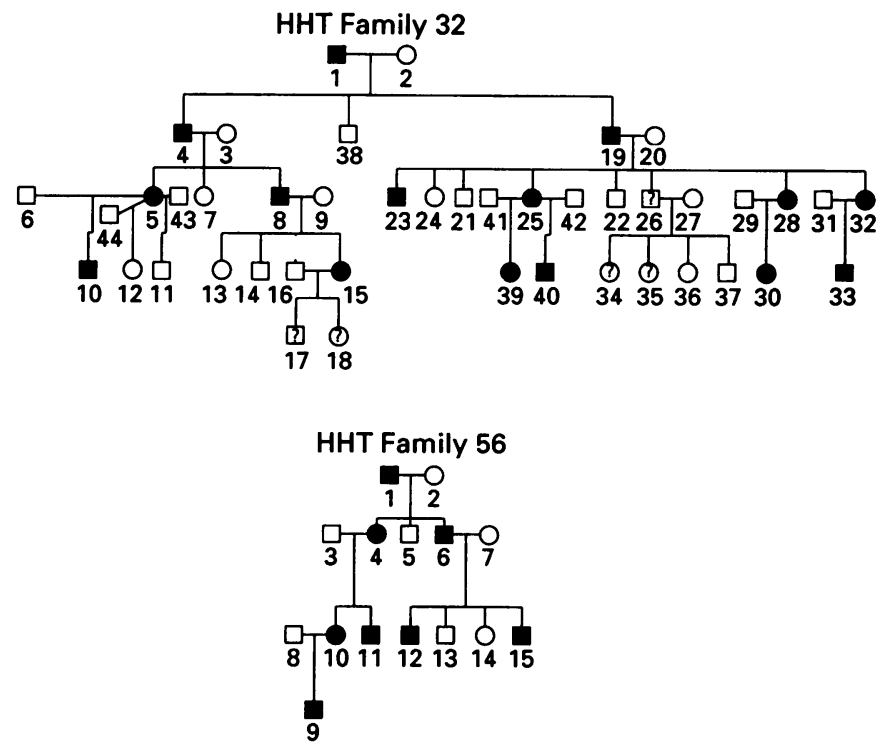

Figure 1 Pedigrees of five new HHT families. Filled symbol, affected; open symbol, unaffected.

\section{Subjects and methods FAMILY DESCRIPTION}

Each participant from the families was interviewed and examined by a medical geneticist. The interview included medical history information such as time of onset and pattern of any epistaxis, evidence for the presence of pulmonary or cerebral arteriovenous malformations, and history of gastrointestinal or pulmonary bleeding. Pertinent medical records, including chest angiography results, were obtained and reviewed when available. Subjects presenting with dyspnoea, cyanosis, or migraine headache were referred for radiological examination for PAVMs. Family history was reviewed. Physical examination included search for telangiectases on the lips, tongue, oral or nasal mucosa, cheeks, fingers, or elsewhere. Affected status was assigned based on the presence of at least two of the following three criteria: telangiectasia, recurrent epistaxis, and an affected first degree relative. ${ }^{2-4}$ Informed consent was obtained and blood samples drawn for DNA extraction, performed using standard methods.

Family 1 is a seven generation pedigree of 322 known persons which includes over 65 members known to have had HHT. The pedigree structure and the linkage of this family to markers on $9 \mathrm{q}$ has been previously published. ${ }^{7}$ Forty persons, of whom 21 were affected, were included in the initial analysis. Since then, an additional 32 family members (of whom 16 are affected) have been collected and included in this study. Thus the entire family sampled now consists of 72 members with 37 affected. (A revised drawing of the pedigree is available upon request.) As is typical in HHT, in this family the most common features of the affected state are epistaxis and telangiectases. Pulmonary arteriovenous malformations are also relatively common in this family; 12 members of the kindred are known to have PAVMs.

Family 2 is a five generation pedigree in which 45 family members have been collected including 20 persons diagnosed as having HHT. This family also has at least eight persons diagnosed with PAVMs. Linkage of this family to markers on $9 q$ and the entire pedigree have been previously described. ${ }^{7}$

Family 17 consists of 28 sampled persons including four affected with HHT. (The pedigree drawings for this and the following families are shown in fig 1.) Nosebleeds and telangiectases are also prevalent in this family. No family member has ever been diagnosed with a PAVM.

Family 32 has 33 collected members spanning five generations, 11 of whom are affected. Epistaxis, telangiectases, cerebral and pulmonary AVMs (in four affected persons: 4, 15, 28 , and 32 ), and brain abscesses are present.

Family 33 consists of 19 sampled persons with seven affected members. Symptoms in the majority of persons designated as affected include epistaxis and telangiectases on the face, lips, tongue, and skin (and in one person, on the abdomen). One person was diagnosed as having cerebral AVM and one died of hepatic failure, although the latter may be unrelated to the HHT. No affected persons had any history of pulmonary AVMs. 
Family 56 consists of 12 collected members including six affected persons. This family, although small, also appears to display the full range of symptoms of HHT, including two persons who have had treatment for PAVMs (Nos 4 and 11).

Family 57 is a four generation kindred with autosomal dominant epistaxis. The initial diagnosis given for this kindred was not HHT, but the epistaxis in this family is not distinguishable from the epistaxis of HHT in terms of frequency, timing, and duration of episodes, age of onset, and response to therapies. However, the six affected members of this pedigree were re-examined and none had telangiectases or any suggestion of such other manifestations of HHT as pulmonary or cerebral AVMs. Twelve sampled members are included in this study, with six affected persons.

\section{GENOTYPING AND LINKAGE ANALYSIS}

Analysis of simple repeat markers was performed as previously described. ${ }^{7}$ HHT was analysed as an autosomal dominant disorder with age dependent penetrance. For estimating the age dependent penetrance, three liability classes were created with age ranges 0-20 (penetrance $0 \cdot 2425), 21-40(0.7275)$ and $>40$ $(0.9700)$. Disease frequency was set at 0.01 . Two point linkage analysis was performed on a Sun Sparc station 10 using the MLINK subprogram of the LINKAGE computer package (version 4.9). ${ }^{9}$ The analysis was repeated using the phenotypic information on only the affected persons to ensure that information was coming only from those with a definitive disease

Table 1 Two point analysis between HHT and chromosome 9q markers

\begin{tabular}{|c|c|c|c|c|c|c|c|}
\hline \multirow{2}{*}{$\begin{array}{l}\text { Marker } \\
\text { and family }\end{array}$} & \multicolumn{7}{|c|}{ Lod score at $\hat{\theta}$} \\
\hline & 0.00 & 0.05 & 0.10 & 0.15 & 0.20 & 0.30 & 0.40 \\
\hline $\begin{array}{c}\text { D9S60 } \\
1 \\
2 \\
17 \\
32 \\
33 \\
56 \\
57 \\
\text { Total }\end{array}$ & $\begin{array}{r}9.70 \\
-x \\
-4.12 \\
-x \\
-2.72 \\
0.33 \\
0.29 \\
-\propto\end{array}$ & $\begin{array}{r}11 \cdot 18 \\
4 \cdot 04 \\
-2 \cdot 22 \\
2 \cdot 47 \\
-0 \cdot 26 \\
0 \cdot 28 \\
0 \cdot 25 \\
15 \cdot 74\end{array}$ & $\begin{array}{r}10 \cdot 21 \\
4 \cdot 27 \\
-1.43 \\
2.64 \\
0 \cdot 17 \\
0 \cdot 24 \\
0 \cdot 20 \\
16 \cdot 30\end{array}$ & $\begin{array}{r}9.06 \\
4.10 \\
-0.95 \\
2.54 \\
0.33 \\
0.19 \\
0.16 \\
15.44\end{array}$ & $\begin{array}{r}7 \cdot 82 \\
3 \cdot 74 \\
-0 \cdot 64 \\
2 \cdot 31 \\
0 \cdot 38 \\
0 \cdot 15 \\
0 \cdot 13 \\
13.89\end{array}$ & $\begin{array}{r}5.11 \\
2.68 \\
-0.25 \\
1.63 \\
0.31 \\
0.07 \\
0.06 \\
9.62\end{array}$ & $\begin{array}{r}2.30 \\
1.36 \\
-0.06 \\
0.75 \\
0.14 \\
0.02 \\
0.02 \\
4.52\end{array}$ \\
\hline $\begin{array}{c}\text { D9S61 } \\
1 \\
2 \\
17 \\
32 \\
33 \\
56 \\
57 \\
\text { Total }\end{array}$ & $\begin{array}{r}2.19 \\
1.30 \\
-2.52 \\
5.99 \\
-4.95 \\
0.60 \\
-x \\
-x\end{array}$ & $\begin{array}{r}2.63 \\
1.21 \\
-1.55 \\
5.51 \\
-2.13 \\
0.54 \\
-2.63 \\
3.56\end{array}$ & $\begin{array}{r}2.43 \\
1.11 \\
-1.03 \\
4.99 \\
-1.35 \\
0.47 \\
-1.77 \\
4.85\end{array}$ & $\begin{array}{r}2.13 \\
0.99 \\
-0.66 \\
4.45 \\
-0.90 \\
0.39 \\
-1.29 \\
5.12\end{array}$ & $\begin{array}{r}1.80 \\
0.87 \\
-0.40 \\
3.88 \\
-0.60 \\
0.32 \\
-0.95 \\
4.91\end{array}$ & $\begin{array}{r}1.09 \\
0.60 \\
-0.09 \\
2.63 \\
-0.24 \\
0.17 \\
-0.51 \\
3.67\end{array}$ & $\begin{array}{r}0.46 \\
0.31 \\
0.02 \\
1.25 \\
-0.06 \\
0.05 \\
-0.21 \\
1.83\end{array}$ \\
\hline $\begin{array}{c}\text { D9S63 } \\
1 \\
2 \\
17 \\
32 \\
33 \\
56 \\
57 \\
\text { Total }\end{array}$ & $\begin{array}{r}6.75 \\
-x \\
-4.99 \\
0.46 \\
-\propto \\
2.41 \\
-\propto \\
-\propto\end{array}$ & $\begin{array}{r}8.60 \\
5.10 \\
-2.73 \\
0.58 \\
-1.64 \\
2.21 \\
-3.08 \\
9.03\end{array}$ & $\begin{array}{r}7.71 \\
5.02 \\
-1.72 \\
0.60 \\
-0.88 \\
2.00 \\
-2.06 \\
10.67\end{array}$ & $\begin{array}{r}6.66 \\
4.66 \\
-1.11 \\
0.58 \\
-0.49 \\
1.78 \\
-1.47 \\
10.59\end{array}$ & $\begin{array}{r}5.52 \\
4.16 \\
-0.70 \\
0.53 \\
-0.27 \\
1.54 \\
-1.07 \\
9.72\end{array}$ & $\begin{array}{r}3.19 \\
2.91 \\
-0.22 \\
0.37 \\
-0.04 \\
1.05 \\
-0.55 \\
6.71\end{array}$ & $\begin{array}{r}1.09 \\
1.45 \\
-0.02 \\
0.18 \\
0.03 \\
0.52 \\
-0.22 \\
3.03\end{array}$ \\
\hline $\begin{array}{r}\text { ASS } \\
1 \\
2 \\
17 \\
32 \\
33 \\
56 \\
57 \\
\text { Total }\end{array}$ & $\begin{array}{r}3.37 \\
-x \\
-0.08 \\
3.97 \\
0.33 \\
1.05 \\
-x \\
-x\end{array}$ & $\begin{array}{r}5.59 \\
3.54 \\
-0.06 \\
3.66 \\
0.34 \\
0.91 \\
-3.27 \\
10.68\end{array}$ & $\begin{array}{r}5.02 \\
3.66 \\
-0.06 \\
3.32 \\
0.33 \\
0.78 \\
-2.21 \\
10.86\end{array}$ & $\begin{array}{r}4.35 \\
3.50 \\
-0.05 \\
2.97 \\
0.30 \\
0.65 \\
-1.59 \\
10.12\end{array}$ & $\begin{array}{r}3.63 \\
3.19 \\
-0.05 \\
2.58 \\
0.25 \\
0.53 \\
-1.16 \\
8.96\end{array}$ & $\begin{array}{r}2.16 \\
2.29 \\
-0.04 \\
1.74 \\
0.15 \\
0.30 \\
-0.59 \\
6.02\end{array}$ & $\begin{array}{r}0.87 \\
1.17 \\
-0.02 \\
0.80 \\
0.07 \\
0.12 \\
-0.23 \\
2.78\end{array}$ \\
\hline
\end{tabular}

status. Multipoint analyses used the $C$ version of LINKAGE distributed by Cottingham $e a^{10}$ known as FASTLINK. First, two point analysis with disease and then multipoint analyses were carried out. Allele frequency estimates for the markers were obtained using the pedigree maximum likelihood estimation from the HHT family data by the method of Boehnke, ${ }^{11}$ and did not differ appreciably from the allele frequencies listed in GDB.

Multipoint analysis was restricted to a location score analysis of HHT with D9S60, D9S61, D9S63, and ASS. These markers were chosen because they were the most highly polymorphic markers in our pedigrees recognising all significant linkage information, and because they cover the region in relatively evenly spaced intervals. Map distances between the markers were as previously reported. ${ }^{12}$ For the multipoint analysis, the data were recoded from the multiallele marker systems to four to six allele systems for computational feasibility. ${ }^{13}$ The two point results under the complete allelic specifications were compared with the recoded data, in order to ensure that all the linkage information was appropriately incorporated into the respecified allelic information. Furthermore, family 1 was broken into seven smaller branches for the multipoint analysis, as the use of the entire family in the analysis, even with down coding, proved computationally intractable. Comparison of the two point results between this entire family and the divided family resulted in loss of less than $10 \%$ of the linkage information. The position of the disease gene was allowed to vary in the intervals demarcated by genetic markers using the LINKAGE subprogram, LINKMAP. Location scores were calculated according to Lathrop et al ${ }^{9}$ and multipoint location scores given as (location score)/4.6. Sex averaged recombination rates were used for this region of the chromosome. ${ }^{12}$

Tests of homogeneity were done by using the admixture test as established in the HOMOG series of programs. ${ }^{14}$ The HOMOG programs analyse three separate hypotheses: HO, the hypothesis of no linkage in any family; $\mathrm{H} 1$, the hypothesis of linkage in all families; and $\mathrm{H} 2$, the hypothesis of linkage in only a subset of families. HOMOG calculates the likelihood of the data under each hypothesis. In the likelihood ratio test, twice the difference in the natural $\log (\ln )$ likelihood ( -2 ln likelihood) is distributed as a $\chi^{2}$ with df equal to the differences in the estimated number of parameters. Heterogeneity is likely if the $\mathrm{H} 1$ versus $\mathrm{H} 2$ test is significant.

\section{Results}

\section{CLINICAL HETEROGENEITY}

A careful survey of the clinical features present in the affected members of our families shows that the families could be sorted into two groups, those in which two or more affected persons had PAVMs (families 1, 2, 32, and 56) and those with no history of members with PAVMs (families 17, 33, and 57). With the exception of family 57 , which only showed 
Table 2 Affecteds only two point analyses

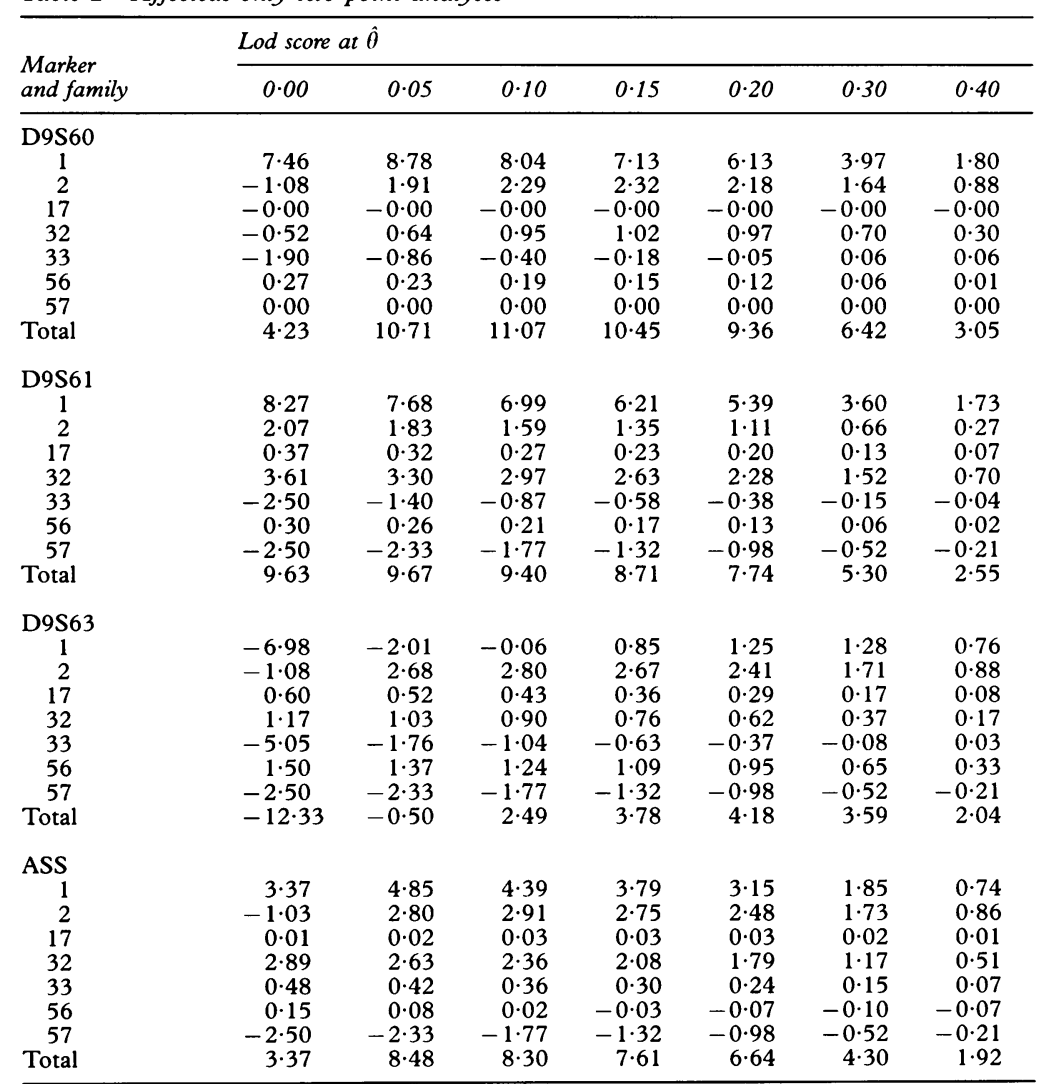

epistaxis, the other clinical features present in each family as a whole were otherwise indistinguishable. All family members in the entire cohort were questioned at length during a physical and medical history for any evidence of PAVM involvement. Pertinent medical records, including chest angiography results, were obtained and reviewed when available. Persons presenting with dyspnoea, cyanosis, or migraine headache were referred for radiological examination for PAVMs. In some cases, persons with undiagnosed PAVMs were discovered.

It is difficult to gain a completely accurate estimate of the incidence of PAVMs in the families that show this feature, since every affected family member has not been tested by chest radiography. Nevertheless, we observed that 26 of the 74 affected members collectively in this group have been diagnosed with PAVMs. The true incidence may be higher than this. The second group of families showed no members diagnosed with PAVMs out of a collective total of 17 affected persons.

\section{LINKAGE ANALYSIS}

A summary of our two point lod scores summed over all seven families is presented in table 1. Peak lod scores of 16.32 (at a maximum recombination fraction $(\hat{\theta})$ of $0 \cdot 09), 5 \cdot 12(\hat{\theta}=$ $0.15), 10.73(\hat{\theta}=0.12)$, and $10.91(\hat{\theta}=0.08)$ were found for the markers D9S60, D9S61, D9S63, and ASS respectively. It is evident from these data that some families show clear evidence of linkage to these markers (families $1,2,32$, and 56) whereas others (families 17 , 33 , and 57) appear to exclude linkage to this region. To ensure that the negative lod scores in the apparently unlinked families were not primarily dependent on the unaffected persons, we repeated lod scores in an affected only analysis (table 2). Although some power was lost because of fewer informative meioses, the results of the affecteds only analysis supports the age adjusted results.

Admixture analysis of two point data using the HOMOG programs results in significant evidence of heterogeneity for markers D9S61 $\left(\chi^{2}=13 \cdot 79, \mathrm{p}=0 \cdot 01\right), \mathrm{D} 9 \mathrm{S63}\left(\chi^{2}=17 \cdot 69, \mathrm{p}=\right.$ $0.01)$, and ASS $\left(\chi^{2}=9.21, \mathrm{p}=0.12\right.$; table 3$)$. Significant evidence of heterogeneity was also shown using affecteds only with markers D9S61 $\left(\chi^{2}=9 \cdot 44, p=0 \cdot 11\right)$, D9S63 $\left(\chi^{2}=9 \cdot 03\right.$, $\mathrm{p}=0.13)$, and ASS $\left(\chi^{2}=5.86, \mathrm{p}=0.0078\right)$. Multipoint analysis was performed with the HHT gene and the four linked markers D9S60, D9S61, D9S63, and ASS (fig 2). Analysis of the entire data set across all families results in a peak multipoint location score of $13.03,10 \mathrm{cM}$ proximal of D9S60. The multipoint analysis supported evidence for heterogeneity, with odds of greater than $3000000: 1$ in favour of linkage and heterogeneity versus linkage and homogeneity. (The In likelihood difference is 15.) On the basis of these analyses, four of the seven families (families 1, 2, 32, and 56) consistently show a posterior probability of greater than $99 \%$ of being linked to chromosome 9q, while three families (families 17, 33 , and 57) appear to be unlinked to this region $(\mathrm{p}<0.01)$.

The multipoint curve generated using only the $9 \mathrm{q} 3$ linked families indicates the most likely location for this locus is between markers D9S60 and D9S63. This location is over 10000 times more likely than a position proximal to this interval and over 1000 times more likely than a position distal to this interval. The multipoint curve generated using families 17, 33 , and 57 clearly excludes the candidate region on $9 \mathrm{q} 3$.

\section{HAPLOTYPE ANALYSIS}

The candidate region for the HHT locus at $9 q 3$ is represented by a number of previously published obligate crossovers involving affected persons. ${ }^{78}$ However, the proximal boundary of the HHT region was defined by a crossover in an unaffected person. ${ }^{8}$ We have now identified critical crossovers in two affected persons from our family 32 (fig 3 ). These two crossovers both occur between D9S60 and D9S61, definitively placing the proximal border of the HHT candidate region at $\mathrm{D} 9 \mathrm{~S} 60$.

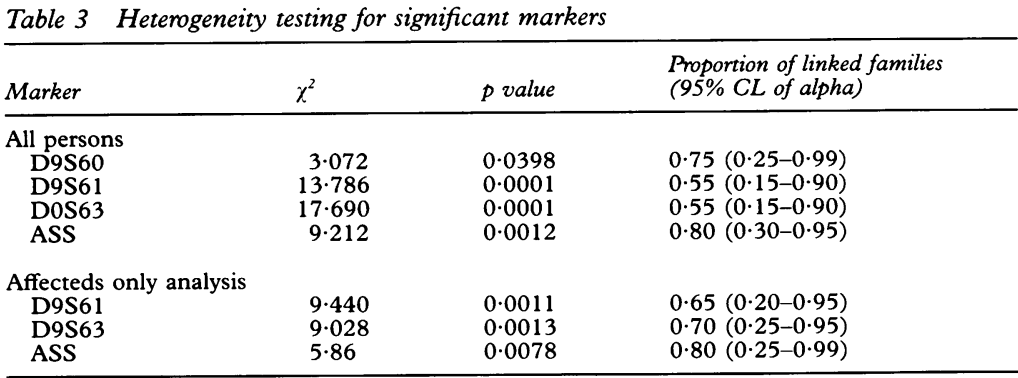




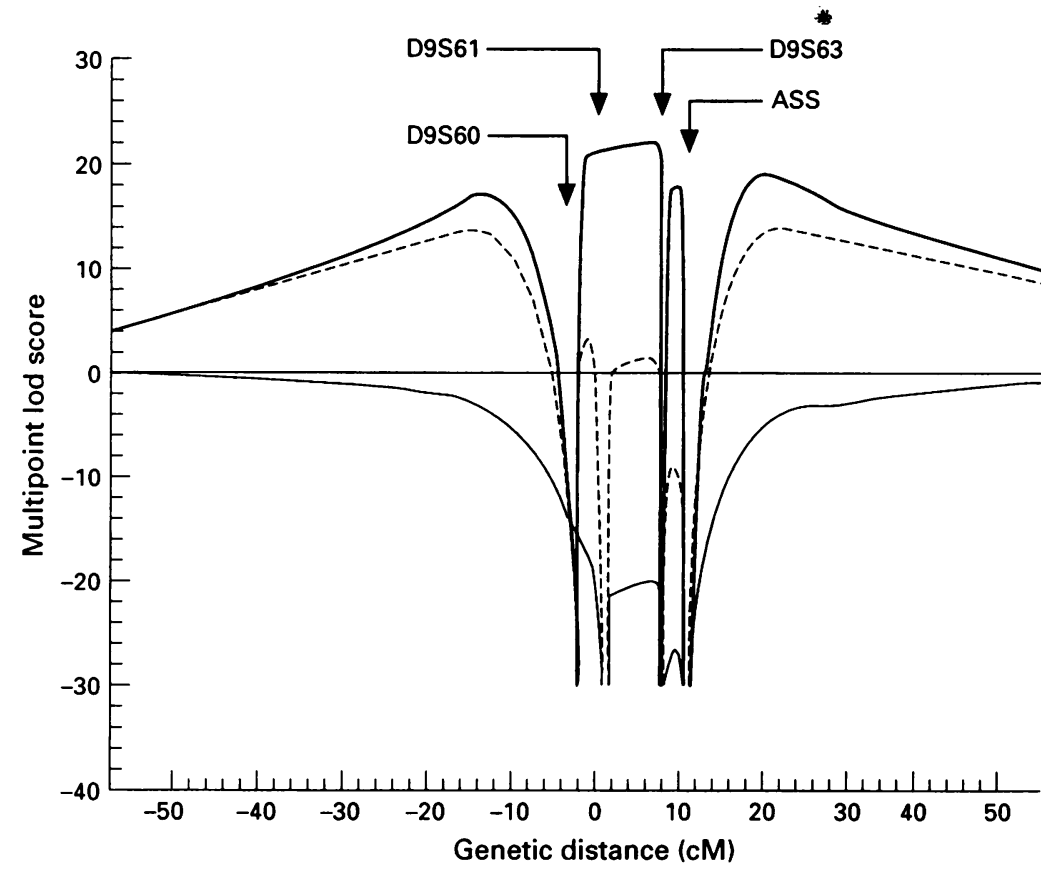

Figure 2 Multipoint location score (log 10 ) curve for HHT and the markers D9S60, D9S61, D9S63, and ASS. The vertical axis represents location scores, while the horizontal axis represents genetic distance (in $c M$ ). Dashed line shows the results for all families, while the thick solid line represents the families with a $>95 \%$ posterior probability of being linked to the chromosome $9 q$ loci. The thin solid lines represent the families with a $<1 \%$ of being linked to these loci. analysis should be used as a diagnostic tool only with extreme caution.

Analyses of our families has shown that those genetically linked to $9 \mathrm{q} 3$ show pulmonary AVMs as a predominant feature, whereas those unlinked to $9 \mathrm{q} 3$ have no known pulmonary involvement. It is striking that in all three of our unlinked families, we have never had a person present with pulmonary AVMs. It is unclear whether this reflects a lower predisposition to the lesion in the unlinked families or whether only the $9 \mathrm{q} 3$ linked families are at any risk for PAVMs. The presence of PAVMs in chromosome 9 linked families may reflect a functional difference in the expression patterns in pulmonary tissue for the chromosome 9 HHT gene compared to the other HHT gene (or genes). Clearly additional families must be ascertained and studied to confirm the correlation seen in this study. However, the results of Shovlin et $a l^{\beta}$ at least in part support the PAVM-9q3 locus correlation, with the exception of a single affected person with a PAVM in an unlinked family.

Family 57 in our study is unusual because members of this pedigree present only with hereditary epistaxis. Although the initial diagnosis was not given as HHT, we have included this family in our cohort because of the historical connection of hereditary epistaxis with HHT. Hereditary epistaxis was first described by Sutton ${ }^{15}$ and Babington, ${ }^{16}$ but Rendu ${ }^{17}$ first described the association of multiple telangiectases with epistaxis. Osler, ${ }^{18}$ Weber, ${ }^{19}$ and Haines ${ }^{20}$ subsequently described additional families with epistaxis and vascular lesions. It is not clear whether the patients described by Sutton $^{15}$ and Babington ${ }^{16}$ were affected by HHT, since only epistaxis is mentioned in their description. Nevertheless, the term SuttonBabington-Rendu-Osler-Weber disease has appeared occasionally in published reports. As family 57 is unlinked to $9 q 3$, we can say that this family presenting with hereditary epistaxis alone does not contain a mutation in the $9 q 3$ HHT locus. Whether this family is linked to the region of the other HHT locus (loci) or whether this clinical presentation is an autosomal dominant disorder distinct from HHT will require the identification of the other HHT gene(s).

Our previously described recombination events in two $9 \mathrm{q} 3$ linked families placed the $9 \mathrm{q} 3$ locus telomeric to $\mathrm{GSN}$ and centromeric to D9S64 in an $18 \mathrm{cM}$ interval. ${ }^{7}$ Additional recombination events tentatively narrowing the candidate region further to an interval flanked by D9S61 and D9S63 were based heavily on the phenotype of a young child in family 1 . Subsequent routine re-examination of this child raised the possibility that his diagnosis may have been mistaken. Owing to the difficulty with his particular diagnosis, particularly considering his age, and the age dependent penetrance associated with this disorder, we have reassigned his phenotype as questionable. However, we have now identified two additional crossovers in affected persons in a new linked family which definitively establish the proximal boundary of the candidate interval at families affected with HHT are too sma determine decisively whether they are linked to the $9 \mathrm{q} 3$ locus. At the present time, linkage 


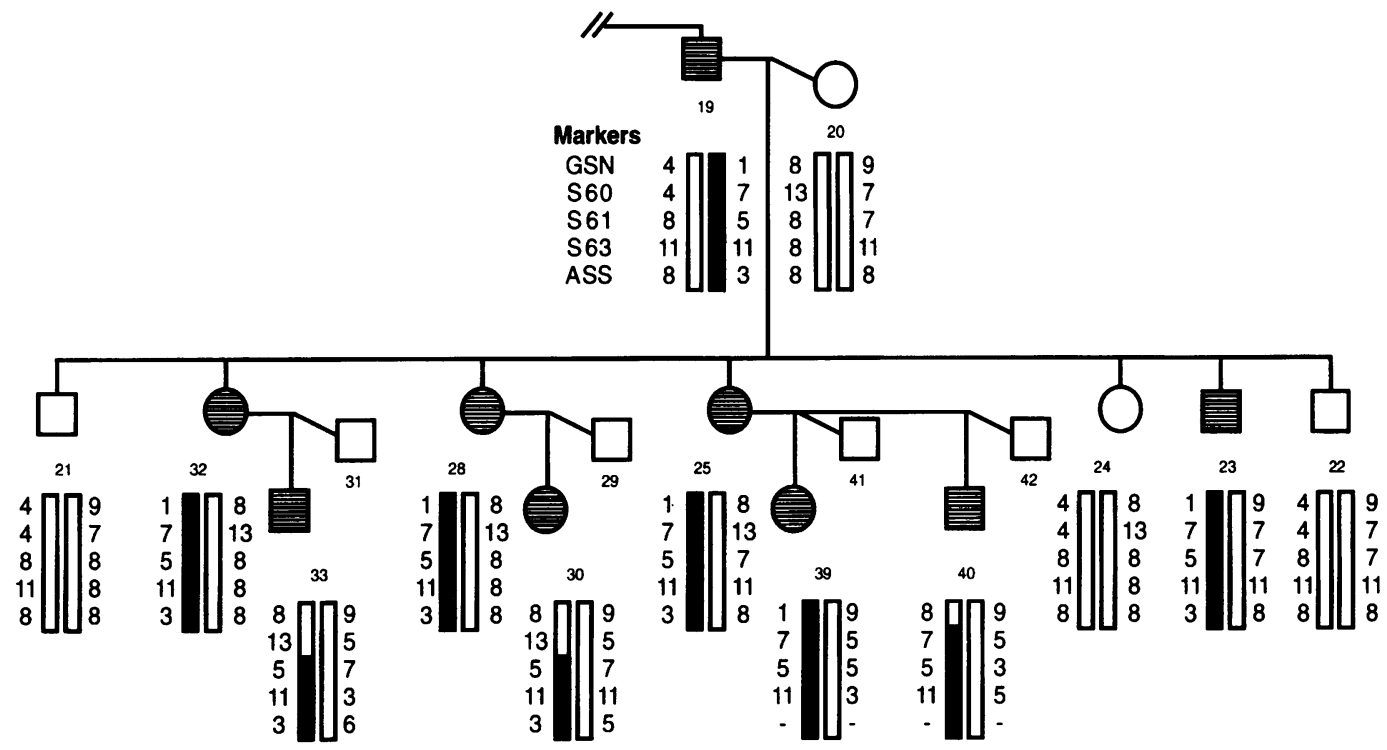

Figure 3 Haplotype analysis of a small branch of family 32. Darkened chromosomes indicate the affected haplotype. Crossovers in affected persons 30 and 33 are illustrated between D9S60 and D9S61, and between GSN and D9S60 in subject 40 .

D9S60. The published recombination events in affected persons place the candidate interval for the $9 \mathrm{q} 3$ HHT gene between D9S60 and D9S61, an interval calculated to be $2 \mathrm{cM} .{ }^{12}$ Using fluorescent in situ hybridisation to interphase nuclei, Leversha $e t a l^{1}$ have estimated the physical distance between D9S60 to D9S61 to be a minimum of 5 megabases and up to 8 megabases. This wide variance is because of the technical difficulty of obtaining accurate measures when intermarker distances are greater than $2 \mathrm{Mb}$. Nevertheless it is clear that the region is much larger than might be predicted and in this region of the chromosome the recombination rate appears to be two to four fold lower than average. Narrowing this candidate region further will require the development of new genetic markers and identification of additional crossovers (in $9 \mathrm{q} 3$ linked HHT families) within this interval.

We hope that further investigation of the possible correlation between pulmonary AVMs and linkage on $9 \mathrm{q} 3$ might indicate the extent to which these persons from $9 \mathrm{q} 3$ linked HHT families are at risk from PAVMs. If the correlation we have noted continues to hold, a clear distinction of the disorder on clinical and molecular grounds might be made. As PAVMs are the cause of much of the morbidity and mortality associated with this disorder, an eventual molecular genetic diagnosis of HHT could have a significant impact on the clinical management and treatment of HHT patients, especially in regard to periodic blood gas and radiological surveillance for HHT patients at risk for PAVMs.

We thank C Fakoya and D Stifler for assistance in family identification and collection, $S$ Kiousis for DNA preparation and $M$ Walsh for lymphocyte immortalisation. We are gratefu to the individual family members who participated in this study and the membership of the Hereditary Hemorrhagic Telangiectasia Foundation, International for their enthusiastic support. This study was supported by NIH grants HL49171 to DAM and NS26330 to MAP-V.
1 Roman G, Fisher M, Perl D, Poser C. Neurological manifestations of hereditary hemorrhagic telangiectasia (Rendu-Osler-Weber disease): report of two cases and review of the literature. Ann Neurol 1978;4:130-44.

2 Porteous MEM, Burn J, Proctor S. Hereditary haemorrhagic telangiectasia: a clinical analysis. $\mathcal{f}$ Med Genet 1992;29: telangiectas

3 Reilly PJ, Nostrant TT. Clinical manifestations of hereditary hemorrhagic telangiectasia. Am f Gastroenterol 1984;79: 363-7.

4 Peery WH. Clinical spectrum of hereditary hemorrhagic telangiectasia (Osler-Weber-Rendu disease). $\mathrm{Am} \mathcal{F} \mathrm{Med}$ 1987;82:989-96.

5 Plauchu H, Chadarevian J-P, Bideau A, Robert J-M. Agerelated clinical profile of hereditary hemorrhagic telangiectasia in an epidemiologically recruited population. Am $\mathcal{J}$ Med Genet 1989;32:291-7.

6 McDonald M, Papenberg K, Ghosh S, et al. Genetic linkage of hereditary hemorrhagic telangiectasia to markers on $9 \mathrm{q}$. of hereditary hemorrhagic telangiectasia to markers

7 McDonald MT, Papenberg KA, Ghosh S, et al. A disease locus for hereditary haemorrhagic telangiectasia maps to locus for hereditary haemorrhagic telangiectasia maps
chromosome 9q33-34. Nature Genet 1994;6:197-204.

8 Shovlin C, Hughes JMB, Tuddenham EGD, et al. A gene for hereditary haemorrhagic telangiectasia maps to chromosome 9q3. Nature Genet 1994;6:205-9.

9 Lathrop GM, Lalouel JM, Julier C, Ott J. Strategies for multilocus linkage analysis in humans. Proc Natl Acad $S c$ USA 1984;8:3443-6.

10 Cotttingham R, Idury R, Schaffer A. Faster sequential genetic linkage computations. Am f Hum Genet 1993;53: 252-63.

11 Boehnke $M$. Allele frequency estimation from data on relatives. Am $\mathcal{F}$ Hum Genet 1989;86:4175-8.

12 Kwiatkowski DJ, Amour J, Bale A, et al. Report on the Second International Workshop on Chromosome 9. Cytogenet Cell Genet 1993;64:93-121.

$13 \mathrm{Ott} \mathrm{K}$. A simple scheme for the analysis of HLA linkage in pedigrees. Am f Hum Genet 1978;51:283-90.

14 Ott J. Analysis of human genetic linkage. Baltimore: Johns Hopkins University Press, 1991

15 Sutton HG. Epistaxis as an indication of impaired nutrition and degeneration of the vascular system. Med Mirror 1864; 1:769-72.

16 Babington BG. Hereditary epistaxis. Lancet 1865;ii:362-3.

17 Rendu H. Epistaxis répétées chez un sujet porteur de petits angiomies cutanés et muqueux. Bull Soc Med Hop (Paris) 1896;13:731.

18 Osler W. On a family form of recurring epistaxis with multiple telangiectases of the skin and mucous memmultiple telangiectases of the skin and mucous

19 Weber FP. Multiple hereditary developmental angiomata (telangiectases) of the skin and mucous membranes as(telangiectases) of the skin and mucous membranes as2.

20 Hanes FM. Multiple hereditary telangiectases causing hemorrhage (hereditary hemorrhagic telangiectasia). Bull fohns Hopkins Hosp 1909;20:63-73.

21 Leversha MA, Carter NP, Ferguson-Smith MA. Physical mapping in $9 \mathrm{q}$ using fluorescent in situ hybridization. Abstracts of the Third International Chromosome 9 Workshop, Cambridge 9-11 April 1994. 